\title{
OPTIMASI PROSES EKSTRAKSI PEKTIN DARI KULIT DAN JERAMI NANGKA (Artocarpus heterophyillus) (KAJIAN RASIO BAHAN PENGENDAP DAN LAMA PENGENDAPAN) MENGGUNAKAN METODE RESPON PERMUKAAN
}

\section{Optimization of Pectin Extraction from Jackfruit (Artocarpus heterophyllus) Rind and Rags (Study of Ratio Precipitant Agent and Precipitation Time) by Response Surface Methodology}

\author{
Kurnia Wulandari*, Simon Bambang Widjanarko \\ Jurusan Teknologi Hasil Pertanian, FTP Universitas Brawijaya Malang \\ JI. Veteran, Malang 65145 \\ *Penulis korespondensi, email: kurniawuland@gmail.com
}

\begin{abstract}
ABSTRAK
Kulit dan jerami buah nangka berpotensi dimanfaatkan menjadi pektin. Ekstraksi pektin dipengaruhi oleh rasio bahan pengendap dan lama pengendapan. Rasio bahan pengendap tertentu dan waktu pengendapan beberapa jam dapat menentukan kualitas pektin sehingga diperlukan penelitian untuk menentukan rasio bahan pengendap dan lama waktu pengendapan agar didapatkan pektin kualitas baik. Tujuan dari penelitian ini untuk mengetahui rasio bahan pengendap dan lama waktu pengendapan yang menghasilkan respon rendemen, derajat esterifikasi dan viskositas pektin yang optimal serta mengetahui karakteristik fisik dan kimia pektin hasil optimasi. Metode optimasi yang digunakan adalah rancangan Central Composite Design (CCD) dari Response Surface Methodology (RSM) dengan 2 faktor yaitu rasio bahan pengendap antara 1:1 sampai 1:3 (v/v) dan lama waktu pengendapan antara 1 sampai 3 jam sehingga menghasilkan 13 perlakuan percobaan. Pada penelitian diperoleh titik optimal pada perlakuan rasio bahan pengendap 1:1.62 (v/v) dan perlakuan lama waktu pengendapan 1.70 jam. Hasil verifikasi menunjukkan bahwa kondisi optimum memiliki nilai rendemen sebesar $4.43 \%$, nilai derajat esterifikasi $71.11 \%$ dan nilai viskositas sebesar $40.5 \mathrm{cP}$.
\end{abstract}

Kata kunci: Ekstraksi pektin, Nangka, Pektin, Pengendapan

\section{ABSTRACT}

Rind and rags of jackfruit was potentially utilized to be pectin. Pectin extraction was influenced by the ratio precipitant agent and the precipitation time. The ratio of precipitant agent and the precipitation time can determine the quality of pectin, so study in determining the ratio of the precipitant agent and the precipitation time to obtain good quality pectin was needed. The aims of the research to know the ratio of the precipitant agent and the precipitation time that would produce optimal yield, degree of esterification and viscosity of pectin, and determine the chemical and physical characteristics of optimized pectin result. Optimization was performed by applying Central Composite Design (CCD) from Response Surface Methodology (RSM) with two factors i.e the ratio of the precipitant agent from 1:1 to $1: 3(\mathrm{~V} / \mathrm{V})$ and the precipitation time from 1 hour to 3 hour, thus there were 13 experimental treatments. This research obtained the optimal point on the ratio of precipitant 1:1.62 (v/v) and the precipitation time 1,70 hours. The result of verification showed that the optimum condition has a yield 4,43\%; the esterification degree $71,11 \%$ and the viscosity $40,5 c P$.

Keywords : Jackfruit, Pectin Extraction, Pectin, Precipitation 


\section{PENDAHULUAN}

Nangka merupakan tanaman yang tumbuh di daerah tropis dan subtropis. Produksi buah nangka di Indonesia pada tahun 2014 sebesar 644.291 ton. Sebagian besar buah nangka yang dihasilkan telah diolah menjadi keripik buah, sari buah, dodol, manisan, sirup, selai, dan pasta yang akan menghasilkan limbah berupa kulit buah, jerami dan biji yang nilainya mencapai $65-80 \%$. Pada industri pembuatan keripik nangka, limbah tersebut akan langsung dibuang dan tidak dimanfaatkan (Kementerian Pertanian, 2015).

Limbah kulit dan jerami buah nangka berpotensi dimanfaatkan menjadi produk yang disebut pektin. Pektin termasuk dalam polisakarida kompleks yang mengandung rantai 1,4- $\alpha-$ D-galaktosiluronik dan dapat diisolasi dari dinding sel tanaman (Sharma et al., 2006). Pektin digunakan secara luas dalam pembentukan gel dan bahan penstabil pada produk sari buah, bahan pembuatan jelly, dan jam (Willat et al., 2006). Ketersediaan pektin komersial di Indonesia masih sangat terbatas dan harus mengimpor dari luar negeri. Oleh karena itu, pengolahan limbah buah nangka menjadi pektin diperlukan dengan tujuan untuk mengurangi impor pektin dari luar negeri. Pada bulan Januari hingga Oktober 2016 data impor pektin Indonesia mencapai $253.297 \mathrm{~kg}$ yang bernilai sebesar 4.225,945 dolar (Badan Pusat Statistik, 2016).

Pektin dapat diperoleh melalui proses ekstraksi. Ekstraksi pektin dilakukan dengan cara ekstraksi menggunakan panas dan larutan asam encer seperti $\mathrm{HCl}$. Ekstraksi pektin dipengaruhi oleh sifat fisik dan cara ekstraksi, salah satunya adalah rasio bahan pengendap dan lama pengendapan. Proses pengendapan dilakukan dengan menambahkan bahan pengendap seperti etanol agar pektin yang terekstraksi dapat terpisah dari larutan asam encer (Batt et al., 2005). Proses pengendapan pektin memerlukan waktu beberapa jam agar pektin benar-benar terpisah dari pelarut. Beberapa penelitian mengenai ekstraksi pektin dari kulit dan jerami nangka telah dilakukan. Akan tetapi, belum adanya penelitian mengenai ekstraksi pektin dari limbah buah nangka dengan kajian rasio bahan pengendap dan lama waktu pengendapan sehingga pada penelitian ini akan dilakukan optimasi proses ekstraksi pektin dengan memperhatikan faktor rasio bahan pengendap dengan filtrat hasil ekstraksi serta lama waktu pengendapan.

\section{BAHAN DAN METODE}

\section{Bahan}

Bahan utama yang digunakan dalam penelitian adalah kulit dan jerami nangka dari UD. Putra Fajar yang terdapat di kota Batu. Bahan yang digunakan pada proses ekstraksi yaitu $\mathrm{HCl} 32 \%$ (Merck), etanol 96\% (Merck), etanol 70\% (Merck) serta akuades. Bahan analisis yang digunakan yaitu $\mathrm{HCl} 0.25 \mathrm{~N}$ (Merck), $\mathrm{NaCl}$ (Merck), enzim alfa amilase, enzim pankreatin, enzim pepsin, etanol 96\%, etanol 95\% (Merck), aseton (Merck), $\mathrm{NaOH} 0.25 \mathrm{~N}$ (Merck), $\mathrm{NaOH} 0.1 \mathrm{~N}$ (Merck), $\mathrm{CaCl}_{2}$ (Merck), sodium sitrat, asam sitrat, indikator PP dan akuades. Pektin komersial sebagai pembanding pektin hasil penelitian diperoleh dari Toko Avia Malang.

\section{Alat}

Peralatan yang digunakan dalam pembuatan tepung kulit dan jerami nangka antara lain cabinet dryer (Omron), blender kering (Vagansa), loyang, pisau dan ayakan 60 mesh. Peralatan yang digunakan dalam proses ekstraksi pektin antara lain shaker waterbath (Memmert W-350), timbangan analitik (Denver Instrument M-310 USA), kabinet lampu, ayakan 60 mesh, glassware (Pyrex), kain saring, bola hisap, baskom, loyang, aluminium foil, spatula, pengaduk, dan pectin container. Peralatan yang digunakan untuk analisis meliputi color reader (Konica Minolta CR-100 Japan), timbangan analitik (Denver Instrument M-310 USA), furnace (Thermolyne), viskosimeter, oven listrik (WTC Binder), desikator (Schott GL 32), tensile strength (Imada), kertas saring, bola hisap dan glassware (Pyrex). 


\section{Tahapan Penelitian}

Tahapan pelaksanaan penelitian terdiri atas tiga tahap :

1. Penepungan kulit dan jerami nangka (Margani, 2014)

Penepungan kulit dan jerami kulit nangka diawali dengan proses sortasi yang bertujuan untuk mendapatkan kulit dan jerami nangka dengan kondisi masih bagus dan segar. Kulit dan jerami nangka kemudian dipotong untuk memperkecil ukuran agar mempercepat waktu pengeringan. Kulit dan jerami nangka yang sudah dipotong kemudian dicuci hingga bersih dan ditimbang sebanyak $6 \mathrm{~kg}$. Kemudian dikeringkan menggunakan pengering kabinet dengan suhu $60^{\circ} \mathrm{C}$ selama \pm 12 jam. Kulit dan jerami nangka kering sebanyak 800 gram kemudian dihaluskan menggunakan blender. Agar tepung yang dihasilkan maksimal, hasil penghancuran kulit dan jerami nangka kemudian diayak menggunakan ayakan 60 mesh.

2. Ekstraksi tepung kulit dan jerami nangka (Margani, 2014; Koh, et al., 2014)

Ekstraksi tepung kulit dan jerami nangka dilakukan dengan menggunakan pemanasan dan pelarut asam encer. Tepung kulit dan jerami nangka diambil sebanyak $10 \mathrm{gram}$ dan dimasukkan ke dalam Erlenmeyer. Setelah itu, ditambahkan larutan $\mathrm{HCl} \mathrm{pH} 1.5$ dengan rasio bahan: pelarut yaitu 1:10 (b/v). Larutan kemudian dikocok hingga tercampur dan dimasukkan ke dalam shaker waterbath. Proses ekstraksi dilakukan pada suhu $80^{\circ} \mathrm{C}$ dengan waktu 2 jam. Setelah proses ekstraksi, larutan tersebut disaring menggunakan kain saring 4 rangkap untuk memisahkan ampas dan filtrat pektin. Filtrat pektin kemudian ditambahkan dengan etanol $96 \%$ sebagai bahan pengendap pektin dengan rasio filtrat : etanol, meliputi: 1:1, 1:2 dan 1:3 dengan lama waktu pengendapan selama 1 jam, 2 jam dan 3 jam. Filtrat dan endapan pektin kasar dipisahkan menggunakan kain saring 4 rangkap. Ekstrak pektin kasar yang tersaring kemudian dicuci sebanyak 2 kali menggunakan etanol 70\% dan dicuci satu kali menggunakan etanol 96\%. Ekstrak pektin yang didapatkan masih dalam bentuk basah sehingga perlu dilakukan pengeringan. Proses pengeringan dilakukan menggunakan pengering lampu dengan suhu $\pm 35^{\circ} \mathrm{C}$ selama 2.5 jam. Setelah kering, pektin dihaluskan menggunakan blender dan diayak menggunakan ayakan 60 mesh.

3. Tahap Verifikasi

Pada tahap ini dilakukan verifikasi hasil optimal dari prediksi model yang didapatkan pada tahap kedua. Kulit dan jerami buah nangka diekstrak dengan metode maserasi menggunakan shaker waterbath dan dilakukan pengendapan dengan rasio dan lama waktu dari hasil solusi program. Dari setiap perlakuan dilakukan analisis rendemen dan derajat esterifikasi. Tahap verifikasi dilakukan dengan tiga kali ulangan dan dibandingkan dengan hasil prediksi optimasi menggunakan Design Expert.

\section{Metode}

Penelitian ini disusun dengan menggunakan metode rancangan Central Composite Design (CCD) dari Kurva Respon Permukaan atau Response Surface Metodology (RSM). Variabel bebas yang digunakan adalah rasio bahan pengendap (filtrat pektin : etanol) (X1) antara 1:1 hingga 1:3 dan lama waktu pengendapan (X2) antara 1 jam hingga 3 jam, sedangkan respon yang akan dioptimasi adalah rendemen (Y1), derajat esterifikasi (Y2) dan viskositas (Y3). Rancangan 13 perlakuan dengan metode RSM dapat pada Tabel 1. 
Tabel 1. Rancangan 13 Perlakuan dengan Metode Kurva Respon Permukaan RSM

\begin{tabular}{|c|c|c|c|c|c|c|}
\hline \multirow[b]{2}{*}{ Id } & \multirow[b]{2}{*}{ Run } & \multicolumn{2}{|c|}{ Variabel Aktual } & \multicolumn{2}{|c|}{$\begin{array}{l}\text { Variabel } \\
\text { Terkode }\end{array}$} & Respon \\
\hline & & $\begin{array}{c}\text { Rasio } \\
\text { filtrat } \\
\text { pektin: } \\
\text { etanol }(v / v)\end{array}$ & $\begin{array}{l}\text { Lama waktu } \\
\text { pengendapan } \\
\quad \text { (jam) }\end{array}$ & $\mathrm{X} 1$ & $\mathrm{X} 2$ & 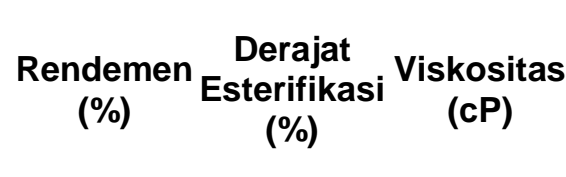 \\
\hline 0 & 1 & 2.00 & 2.00 & 0.00 & 0.00 & \\
\hline 0 & 11 & 2.00 & 2.00 & 0.00 & 0.00 & \\
\hline 0 & 3 & 2.00 & 2.00 & 0.00 & 0.00 & \\
\hline 0 & 12 & 2.00 & 2.00 & 0.00 & 0.00 & \\
\hline 0 & 4 & 2.00 & 2.00 & 0.00 & 0.00 & \\
\hline 1 & 2 & 1.00 & 1.00 & -1.00 & -1.00 & \\
\hline 2 & 13 & 3.00 & 1.00 & 1.00 & -1.00 & \\
\hline 3 & 9 & 1.00 & 3.00 & -1.00 & 1.00 & \\
\hline 4 & 7 & 3.00 & 3.00 & 1.00 & 1.00 & \\
\hline 5 & 8 & 0.59 & 2.00 & -1.41 & 0.00 & \\
\hline 6 & 6 & 3.41 & 2.00 & 1.41 & 0.00 & \\
\hline 7 & 10 & 2.00 & 0.59 & 0.00 & -1.41 & \\
\hline 8 & 5 & 2.00 & 3.41 & 0.00 & 1.41 & \\
\hline
\end{tabular}

\section{Prosedur Analisis}

Pektin hasil ekstraksi dilakukan analisis utama berupa rendemen, berat ekivalen, kadar metoksil, kadar asam galakturonat, derajat esterifikasi dan viskositas.

1. Rendemen (Bambang dkk., 1998)

Bahan baku yang diekstrak ditimbang beratnya $(A)$, kemudian pektin kering yang diperoleh juga ditimbang beratnya (B).

Rendemen $=\frac{\mathrm{B}}{\mathrm{A}} \times 100 \%$

2. Berat Ekivalen (Ranganna, 1977)

$0.5 \mathrm{gr}$ pektin dimasukkan ke erlenmeyer $250 \mathrm{ml}$ dan ditambahkan dengan $5 \mathrm{ml}$ etanol, 1 gr NaCl, $100 \mathrm{ml}$ air bebas $\mathrm{CO}_{2}$ dan 6 tetes indikator PP. Dititrasi dengan $\mathrm{NaOH} 0.1 \mathrm{~N}$ hingga dihasilkan warna merah muda.

$\mathrm{BE}=\frac{\text { gr sampel } \times 1000}{\mathrm{ml} \mathrm{NaOH} \times \mathrm{N} \mathrm{NaOH}}$

3. Kadar Metoksil (Ranganna, 1977)

Larutan hasil analisis berat ekivalen ditambahkan $25 \mathrm{ml} \mathrm{NaOH} 0.25 \mathrm{~N}$, dikocok dan ditutup. Kemudian diamkan 30 menit di suhu kamar. Ditambahkan $25 \mathrm{ml} \mathrm{HCl} \mathrm{0,.25} \mathrm{N.}$ Dititrasi dengan $\mathrm{NaOH} 0.1 \mathrm{~N}$ hingga dihasilkan warna merah muda.

Kadar Metoksil $(\%)=\frac{\mathrm{ml} \mathrm{NaOH} \mathrm{x} \mathrm{N} \mathrm{NaOH} \mathrm{x} \mathrm{3,1}}{\text { gr sampel }}$

4. Kadar Asam Galakturonat (McCready, 1970)

Asam galakturonat $(\%)=\frac{\operatorname{mek}(\mathrm{BE}+\mathrm{KM}) \times 176}{\mathrm{mg} \mathrm{sampel}} \times 100 \%$

5. Derajat Esterifikasi (Schultz, 1965)

Derajat Esterifikasi $(\%)=\frac{176 \times \% \text { metoksil } \times 100}{31 \times \% \text { asam galakturonat }}$

6. Viskositas (Kar and Arslan, 1999)

Satu gram sampel pektin dilarutkan dalam akuades hingga $100 \mathrm{ml}$. Sampel dinetralkan dengan $\mathrm{NaOH} 0.1 \mathrm{~N}$ hingga $\mathrm{pH}$ 7. Sampel disimpan pada suhu ruang selama 12 jam. Larutan pektin diuji viskositas dengan menggunakan viskosimeter.

Pektin hasil perlakuan optimal akan dilakukan analisis tambahan yaitu kadar abu (Sudarmadji, dkk., 1997), kadar air (Sudarmadji, dkk., 1997), kekuatan gel (Yuwono dan 
Susanto, 1998), sineresis (Yuwono dan Susanto, 1998), warna (Yuwono dan Susanto, 1998) dan serat pangan (Sudarmadji, dkk., 1997), dan dibandingkan dengan pektin komersial.

\section{HASIL DAN PEMBAHASAN}

Pada penelitian ini, faktor yang ingin dioptimasi pada proses ekstraksi pektin kulit dan jerami nangka adalah rasio bahan pengendap dan lama waktu pengendapan. Hasil analisis rasio bahan pengendap (filtrat pektin : bahan pengendap etanol) dan lama waktu pengendapan terhadap rendemen, derajat esterifikasi dan viskositas dapat dilihat pada Tabel 2.

Tabel 2. Hasil Analisis Perlakuan Percobaan

\begin{tabular}{|c|c|c|c|c|c|c|c|c|}
\hline \multirow[b]{2}{*}{ Id } & \multirow[b]{2}{*}{ Run } & \multicolumn{2}{|c|}{ Variabel Aktual } & \multicolumn{2}{|c|}{$\begin{array}{c}\text { Variabel } \\
\text { Kode }\end{array}$} & \multicolumn{3}{|c|}{ Respon } \\
\hline & & $\begin{array}{c}\text { Rasio } \\
\text { Filtrat } \\
\text { Pektin : } \\
\text { Etanol } \\
(\mathrm{v} / \mathrm{v})\end{array}$ & $\begin{array}{l}\text { Lama Waktu } \\
\text { Pengendapan } \\
\text { (jam) }\end{array}$ & $\mathrm{X} 1$ & $\mathrm{x} 2$ & $\begin{array}{c}\text { Rendemen } \\
(\%)\end{array}$ & $\begin{array}{c}\text { Derajat } \\
\text { Esterifikasi } \\
(\%)\end{array}$ & $\begin{array}{l}\text { Viskositas } \\
\text { (cp) }\end{array}$ \\
\hline 0 & 1 & 2.00 & 2.00 & 0.00 & 0.00 & 4.86 & 68.99 & 39.00 \\
\hline 0 & 11 & 2.00 & 2.00 & 0.00 & 0.00 & 4.29 & 74.45 & 39.00 \\
\hline 0 & 3 & 2.00 & 2.00 & 0.00 & 0.00 & 4.26 & 72.10 & 43.50 \\
\hline 0 & 12 & 2.00 & 2.00 & 0.00 & 0.00 & 4.63 & 75.35 & 44.00 \\
\hline 0 & 4 & 2.00 & 2.00 & 0.00 & 0.00 & 4.77 & 72.53 & 41.00 \\
\hline 1 & 2 & 1.00 & 1.00 & -1.00 & -1.00 & 4.10 & 67.07 & 35.25 \\
\hline 2 & 13 & 3.00 & 1.00 & 1.00 & -1.00 & 4.48 & 67.61 & 40.00 \\
\hline 3 & 9 & 1.00 & 3.00 & -1.00 & 1.00 & 4.46 & 69.21 & 50.00 \\
\hline 4 & 7 & 3.00 & 3.00 & 1.00 & 1.00 & 4.88 & 71.11 & 20.50 \\
\hline 5 & 8 & 0.59 & 2.00 & -1.41 & 0.00 & 4.32 & 65.95 & 40.00 \\
\hline 6 & 6 & 3.41 & 2.00 & 1.41 & 0.00 & 4.93 & 70.86 & 33.00 \\
\hline 7 & 10 & 2.00 & 0.59 & 0.00 & -1.41 & 4.60 & 60.90 & 43.00 \\
\hline 8 & 5 & 2.00 & 3.41 & 0.00 & 1.41 & 4.69 & 68.32 & 35.25 \\
\hline
\end{tabular}

Keterangan : $\quad \mathrm{X} 1=$ Rasio Filtrat Pektin : Bahan Pengendap Etanol (v/v). X2 = Lama Waktu Pengendapan (jam)

Tabel 2 menunjukkan hasil 13 perlakuan ekstraksi pektin. Rendemen pektin tertinggi didapatkan pada rasio bahan pengendap 1:3.41 (v/v) dan lama waktu pengendapan 2 jam dan rendemen terendah didapatkan pada rasio bahan pengendap 1: $1(\mathrm{v} / \mathrm{v})$ dan lama waktu pengendapan 1 jam. Derajat esterifikasi tertinggi didapatkan pada rasio bahan pengendap 1:2 $(\mathrm{v} / \mathrm{v})$ dan lama waktu pengendapan selama 2 jam dan derajat esterifikasi terendah didapatkan pada rasio bahan pengendap 1:2 (v/v) dan lama waktu pengendapan selama 0.59 jam. Viskositas pektin tertinggi terdapat pada rasio bahan pengendap 1:1 (v/v) dan lama waktu pengendapan selama 3 jam dan viskositas terendah diperoleh pada rasio bahan pengendap $1: 3(\mathrm{v} / \mathrm{v})$ dan lama waktu pengendapan 3:3.

\section{Analisis Respon Rendemen Pektin}

Pengaruh rasio bahan pengendap dan lama pengendapan terhadap rendemen pektin dapat dilihat dengan analisis ragam menggunakan uji ANOVA (Analysis of Variance). Data analisis ragam ANOVA rendemen pektin dapat dilihat pada Tabel 3. 
Tabel 3 Analisis Ragam Anova Respon Rendemen

\begin{tabular}{lcccccc}
\hline \multicolumn{1}{c}{ Sumber Keragaman } & $\begin{array}{c}\text { Jumlah } \\
\text { Kuadrat }\end{array}$ & Df & $\begin{array}{c}\text { Rata- } \\
\text { rata } \\
\text { Kuadrat }\end{array}$ & $\begin{array}{c}\mathbf{F} \\
\text { Hitung }\end{array}$ & $\begin{array}{c}\text { Nilai } \mathbf{P} \\
\text { Prob>F }\end{array}$ & Keterangan \\
Model & 0.4436 & 2 & 0.2218 & 5.5684 & 0.0237 & signifikan \\
A-Rasio Bahan Pengendap & 0.3443 & 1 & 0.3443 & 8.6449 & 0.0148 & signifikan \\
B-Lama Waktu & 0.0992 & 1 & 0.0992 & 2.4918 & 0.1455 & tidak \\
Pengendapan & 0.3983 & 10 & 0.0398 & & & \\
Residu & 0.1009 & 6 & 0.0168 & 0.2262 & 0.9473 & tidak \\
Lack of Fit & 0.2974 & 4 & 0.0743 & & & \\
Galat & 0.8418 & 12 & & & & \\
Total & & & & & & \\
\hline
\end{tabular}

Berdasarkan uji ANOVA pada Tabel 3 didapatkan nilai $P$ untuk model sebesar 0.0237 atau lebih kecil dari $5 \%$ yang berarti model signifikan terhadap respon. Nilai $P$ pada perlakuan rasio bahan pengendap sebesar 0.0148 yang berarti perlakuan rasio bahan pengendap memberikan pengaruh yang signifikan terhadap rendemen pektin. Semakin tinggi rasio bahan pengendap maka semakin tinggi rendemen yang didapatkan. Alkohol seperti etanol dan isopropanol digunakan untuk mengganggu ikatan hidrogen antara air dan pektin sehingga pektin akan saling terikat satu dengan lainnya. Konsentrasi alkohol yang tinggi (rasio 1:3 v/v) memberikan hasil pektin terbaik. Air yang ada pada sekeliling pektin akan diikat oleh alkohol melalui ikatan hidrogen sehingga kesetimbangan air dan pektin akan terganggu dan pektin akan terkoagulasi (Yapo, et al., 2007).

Perlakuan lama waktu pengendapan memiliki nilai $P$ sebesar 0.1455 atau lebih besar dari $5 \%$ yang berarti perlakuan lama waktu pengendapan tidak signifikan memberikan pengaruh terhadap rendemen pektin. Hasil tersebut sesuai dengan penelitian sebelumnya yang menunjukkan bahwa perlakuan pengendapan 60 menit menghasilkan rendemen $1.10 \%$, waktu pengendapan 120 menit menghasilkan rendemen sebesar $1.30 \%$ dan waktu pengendapan 180 menghasilkan rendemen sebesar $1.40 \%$ (Garna, et al., 2007). Waktu 1 jam hingga 3 jam tidak terlalu banyak memberikan pengaruh terhadap nilai rendemen pektin yang dihasilkan. Hal tersebut dapat dikarenakan rentan waktu yang digunakan terlalu dekat sehingga proses koagulasi pada masing-masing waktu tidak menunjukkan pengaruh dan hasil yang berbeda.

Lack of Fit dari respon rendemen pektin pada Tabel 3 menunjukkan nilai P sebesar 0.9473 atau lebih besar dari 5\% yang menunjukkan bahwa nilai ketidaktepatan data respon rendemen pektin tidak signifikan. Model yang disarankan oleh program adalah model linier. Persamaan linier yang didapatkan untuk respon rendemen pektin yaitu $\mathrm{Y}=3.92217+$ $0.20146 \mathrm{X} 1+0.11138 \mathrm{X} 2$.

Pada persamaan tersebut, $\mathrm{X} 1$ merupakan rasio bahan pengendap (v/v) sedangkan $\mathrm{X} 2$ merupakan lama waktu pengendapan (jam). Model linier untuk rendemen pektin menunjukkan bahwa semakin tinggi rasio bahan pengendap dan lama waktu pengendapan maka semakin tinggi hasil rendemen pektin yang didapatkan.

Hubungan antara perlakuan rasio bahan pengendap dan lama waktu pengendapan terhadap rendemen pektin dapat digambarkan dalam bentuk kurva permukaan respon yang dapat dilihat pada Gambar 1. Gambar 1 menunjukkan kurva permukaan respon variabel rasio bahan pengendap dan lama waktu pengendapan terhadap respon rendemen adalah model kurva linier. Faktor rasio bahan pengendap menunjukkan pengaruh yang signifikan terhadap respon (Tabel 3). Berdasarkan Gambar 1, perubahan rasio pengendapan dengan waktu pengendapan yang sama memperlihatkan adanya perubahan warna. Perubahan warna menunjukkan bahwa perlakuan rasio bahan pengendapan memberikan pengaruh yang signifikan terhadap rendemen pektin. Faktor lama waktu pengendapan menunjukkan pengaruh yang tidak signifikan terhadap respon (Tabel 3). Hal tersebut dapat dilihat pada perubahan warna kurva (Gambar 1). Berdasarkan Gambar 1, perubahan waktu pengendapan 
dengan rasio pengendapan yang sama tidak terlalu memperlihatkan perubahan warna. Perubahan warna yang sedikit menunjukkan bahwa perlakuan lama waktu pengendapan pada penelitian memberikan pengaruh yang tidak signifikan terhadap rendemen pektin.

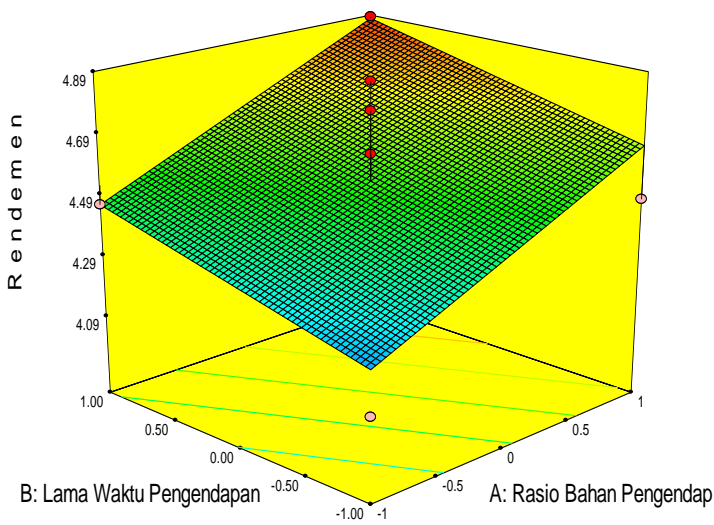

Gambar 1. Kurva Pengaruh Rasio Bahan Pengendap dan Lama Waktu Pengendapan terhadap Rendemen Pektin

\section{Analisis Respon Derajat Esterifikasi Pektin}

Pengaruh rasio bahan pengendap dan lama pengendapan terhadap derajat esterifikasi pektin dapat dilihat dengan analisis ragam menggunakan uji ANOVA (Analysis of Variance). Data analisis ragam ANOVA derajat esterifikasi pektin dapat dilihat pada Tabel 4.

Tabel 4 Analisis Ragam Anova Respon Derajat Esterifikasi

\begin{tabular}{lcccccl}
\hline \multicolumn{1}{c}{ Sumber Keragaman } & $\begin{array}{c}\text { Jumlah } \\
\text { Kuadrat }\end{array}$ & Df & $\begin{array}{c}\text { Rata- } \\
\text { rata } \\
\text { Kuadrat }\end{array}$ & $\begin{array}{c}\mathbf{F} \\
\text { Hitung }\end{array}$ & $\begin{array}{c}\text { Nilai P } \\
\text { Prob>F }\end{array}$ & Keterangan \\
\hline Model & 137.0616 & 5 & 27.4123 & 4.8286 & 0.0313 & Signifikan \\
A-Rasio Bahan Pengendap & 11.0043 & 1 & 11.0043 & 1.9384 & 0.2065 & Tidak signifikan \\
B-Lama Waktu Pengendapan & 32.5552 & 1 & 32.5552 & 5.7345 & 0.0478 & Signifikan \\
AB & 0.4612 & 1 & 0.4612 & 0.0812 & 0.7839 & Tidak signifikan \\
A $2^{\wedge} 2$ & 17.3013 & 1 & 17.3013 & 3.0476 & 0.1244 & Tidak signifikan \\
B^2 & 84.1080 & 1 & 84.1080 & 14.8154 & 0.0063 & Signifikan \\
Residu & 39.7395 & 7 & 5.6771 & & & \\
Lack of Fit & 15.5324 & 3 & 5.1775 & 0.8555 & 0.5324 & Tidak signifikan \\
Galat & 24.2070 & 4 & 6.0518 & & & \\
Total & 176.8011 & 12 & & & & \\
\hline
\end{tabular}

Pengaruh rasio bahan pengendap dan lama pengendapan terhadap derajat esterifikasi pektin dapat dilihat dengan analisis ragam menggunakan uji ANOVA (Analysis of Variance). Hasil analisis ragam menggunakan ANOVA pada Tabel 4 menunjukkan bahwa nilai $P$ untuk model sebesar 0.0313 atau kurang dari $5 \%$ yang berarti model signifikan terhadap respon. Nilai $P$ pada perlakuan rasio bahan pengendap sebesar 0.2065 atau lebih dari $5 \%$ yang berarti perlakuan rasio bahan pengendap tidak signifikan memberikan pengaruh terhadap derajat esterifikasi. Hasil tersebut sesuai dengan penelitian sebelumnya yaitu rasio bahan pengendap mempengaruhi derajat esterifikasi pektin. Pada rasio 1:0.5 diperoleh derajat esterifikasi sebesar $68.36 \%$. rasio $1: 1$ diperoleh derajat esterifikasi sebesar $85.86 \%$. rasio 1:1.5 diperoleh derajat esterifikasi sebesar $75.46 \%$ dan rasio 1:2.5 diperoleh derajat esterifikasi sebesar 74.62\% (Faravash and Ashtiani, 2007). Perbedaan tersebut dapat dipengaruhi oleh kondisi pengendapan. Pada literatur proses pengendapan dilakukan dalam kondisi asam yaitu $\mathrm{pH} 2.5$. 
Pada perlakuan lama waktu pengendapan memiliki nilai $P$ sebesar 0.0478 yang berarti lama waktu pengendapan memberikan pengaruh signifikan terhadap derajat esterifikasi. Semakin lama waktu kontak antara filtrat hasil ekstraksi dan alkohol menyebabkan derajat esterifikasi yang awalnya naik lama-lama akan semakin menurun. Penggunakan bahan pengendap berupa etanol mampu menyebabkan suasana menjadi asam karena etanol dapat melepaskan ion $\mathrm{H}^{+}$sehingga terjadi reaksi deesterifikasi. Reaksi deesterifikasi menyebabkan nilai derajat esterifikasi yang terhitung menjadi rendah (Pudjaatmaka, 1994).

Nilai Lack of Fit dari respon derajat esterifikasi (Tabel 4) sebesar 0.5324 atau lebih dari $5 \%$ yang berarti nilai ketidaktepatan pada nilai derajat esterifikasi kecil atau tidak signifikan. Persamaan yang didapatkan untuk respon derajat esterifikasi yaitu

$Y=47.44564+6.80186 X 1+15.2467 X 2+0.33958 X 1 X 2-1.57704 X 1^{2}-3.47714 X 2^{2}$

Pada persamaan tersebut, $\mathrm{X} 1$ merupakan rasio bahan pengendap $(\mathrm{v} / \mathrm{v})$ sedangkan $\mathrm{X} 2$ merupakan lama waktu pengendapan (jam). Model kuadratik untuk rendemen pektin menunjukkan bahwa semakin tinggi rasio bahan pengendap dan lama waktu pengendapan maka semakin tinggi derajat esterifikasi pektin yang didapatkan. Akan tetapi, peningkatan rasio pengendap dan lama waktu pengendapan secara terus menerus akan menyebabkan terjadinya penurunan derajat esterifikasi.

Hubungan antara perlakuan rasio bahan pengendap dan lama waktu pengendapan terhadap derajat esterifikasi dapat digambarkan dalam bentuk kurva permukaan respon yang dapat dilihat pada Gambar 2. Gambar 2 menunjukkan kurva permukaan respon variabel rasio bahan pengendap dan lama waktu pengendapan terhadap respon derajat esterifikasi yang menghasilkan model kurva kuadratik.

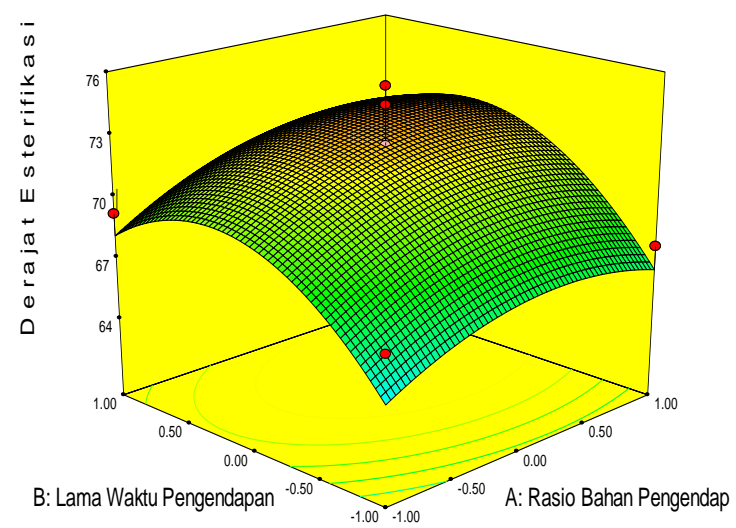

Gambar 2. Kurva Pengaruh Rasio Bahan Pengendap dan Lama Waktu Pengendapan terhadap Derajat Esterifikasi Pektin

\section{Analisis Respon Viskositas Pektin}

Pengaruh rasio bahan pengendap dan lama pengendapan terhadap viskositas pektin dapat dilihat dengan analisis ragam menggunakan uji ANOVA (Analysis of Variance). Data analisis ragam ANOVA viskositas pektin dapat dilihat pada Tabel 5.

Tabel 5. Analisis Ragam Anova Respon Viskositas

\begin{tabular}{lcccccc}
\hline \multicolumn{1}{c}{ Sumber Keragaman } & $\begin{array}{c}\text { Jumlah } \\
\text { Kuadrat }\end{array}$ & df & $\begin{array}{c}\text { Rerata } \\
\text { Kuadrat }\end{array}$ & $\begin{array}{c}\mathbf{F} \\
\text { Hitung }\end{array}$ & $\begin{array}{c}\text { Nilai P } \\
\text { Prob>F }\end{array}$ & Keterangan \\
\hline Model & 474.1902 & 3 & 158.0634 & 11.9051 & 0.0017 & signifikan \\
A-Rasio Bahan Pengendap & 150.0734 & 1 & 150.0734 & 11.3033 & 0.0084 & signifikan \\
B-Lama Waktu Pengendapan & 30.8511 & 1 & 30.8511 & 2.3237 & 0.1618 & Tidak signifikan \\
AB & 293.2656 & 1 & 293.2656 & 22.0883 & 0.0011 & signifikan \\
Residual & 119.4925 & 9 & 13.277 & & & \\
Lack of Fit & 96.6925 & 5 & 19.3385 & 3.3927 & 0.1300 & Tidak signifikan \\
Galat & 22.8 & 4 & 5.7 & & & \\
Total & 593.6827 & 12 & & & & \\
\hline
\end{tabular}


Pengaruh rasio bahan pengendap dan lama pengendapan terhadap viskositas pektin dapat dilihat dengan analisis ragam menggunakan uji ANOVA (Analysis of Variance). Hasil analisis ragam menggunakan ANOVA pada Tabel 5 menunjukkan bahwa nilai $P$ untuk model sebesar 0.0017 atau kurang dari $5 \%$ yang berarti model signifikan terhadap respon. Nilai $P$ pada perlakuan rasio bahan pengendap sebesar 0.0084 atau kurang dari $5 \%$ yang berarti perlakuan rasio bahan pengendap memberikan pengaruh terhadap viskositas pektin. Pada perlakuan lama waktu pengendapan memiliki nilai $P$ sebesar 0.1618 yang berarti lama waktu pengendapan tidak memberikan pengaruh yang signifikan terhadap viskositas pektin. Antara kedua perlakuan saling berpengaruh secara signifikan terhadap respon viskositas pektin yang ditunjukkan dengan nilai $P$ untuk $A B$ sebesar 0.0011 atau kurang dari $5 \%$. Semakin besar rasio bahan pengendap menghasilkan viskositas pektin yang semakin meningkat dan semakin lama waktu pengendapan menghasilkan viskositas pektin meningkat secara tidak signifikan. Lama waktu pengendapan tidak berpengaruh nyata terhadap viskositas yang ditunjukkan dengan nilai P diatas 5\% yaitu sebesar 0.1114 (Prabowo, 2017).

Nilai Lack of Fit dari respon derajat esterifikasi sebesar 0.1300 atau lebih dari $5 \%$ yang berarti nilai ketidaktepatan pada nilai derajat esterifikasi kecil atau tidak signifikan. Persamaan yang diperoleh untuk respon viskositas pektin yaitu

$$
Y=17.07068+12.79381 X 1+15.16123 X 2-8.5625 X 1 X 2
$$

Pada persamaan tersebut, $\mathrm{X} 1$ merupakan rasio bahan pengendap $(\mathrm{v} / \mathrm{v})$ sedangkan $\mathrm{X} 2$ merupakan lama waktu pengendapan (jam). Pada respon viskositas pektin memiliki model dan bentuk persamaan 2FI. Model 2FI menunjukkan bahwa kedua faktor saling berpengaruh pada viskositas pektin.

Hubungan antara perlakuan rasio bahan pengendap dan lama waktu pengendapan terhadap viskositas pektin dapat digambarkan dalam bentuk kurva permukaan respon yang dapat dilihat pada Gambar 3. Gambar 3 menunjukkan kurva permukaan respon variabel rasio bahan pengendap dan lama waktu pengendapan terhadap respon viskositas yang menghasilkan model kurva 2FI. Viskositas pektin dapat dipengaruhi oleh kemurnian pektin. Rasio bahan pengendap semakin besar dan lama waktu pengendapan semakin lama dapat menyebabkan semakin banyak senyawa pengotor yang ikut terendapkan. Pektin selain tersusun dari asam-asam galakturonat juga dapat berikatan dengan gula, mineral dan sedikit protein(Sharma et al., 2006). Presipitasi etanol dari serat larut seperti pektin memungkinkan adanya komponen nonfiber seperti gula, asam organik dan garam yang ikut terendapkan (Manas and Calixto, 1993). Adanya senyawa pengotor dapat mempengaruhi nilai viskositas pektin ketika dianalisis menggunakan viskosimeter.

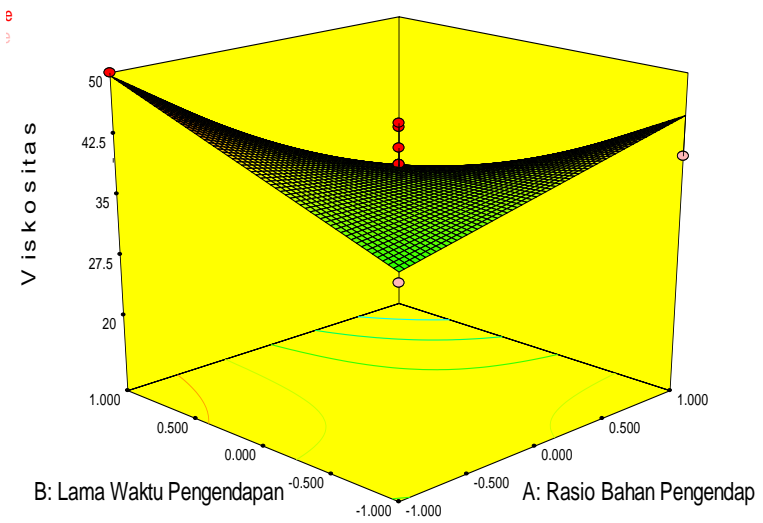

Gambar 3. Kurva Pengaruh Rasio Bahan Pengendap dan Lama Waktu Pengendapan terhadap Viskositas Pektin

\section{Verifikasi Hasil Optimum}

Nilai optimasi dipilih berdasarkan nilai desirability. Nilai desirability mendekati nilai 1.0 menunjukkan kemampuan program menghasilkan produk yang dikehendaki semakin 
sempurna. Tahapan optimasi tidak bertujuan untuk memperoleh nilai desirability 1.0 tetapi untuk mencari kondisi terbaik yang mempertemukan semua fungsi tujuan (Raissi and Farzani, 2009). Setelah didapatkan rasio bahan pengendap dan lama waktu pengendapan optimal dilakukan proses validasi. Proses verifikasi dilakukan sebanyak tiga kali ulangan dan hasilnya dibandingkan dengan hasil prediksi pada program Design Expert. Hasil verifikasi data titik optimal dapat dilihat pada Tabel 6.

Tabel 6 Data Verifikasi Hasil Optimum

\begin{tabular}{lccccc}
\hline & \multicolumn{3}{c}{ Variabel Bebas } & \multicolumn{3}{c}{ Respon } \\
\hline & $\begin{array}{c}\text { Rasio Bahan } \\
\text { Pengendap } \\
(\mathrm{v} / \mathrm{v})\end{array}$ & $\begin{array}{c}\text { Lama Waktu } \\
\text { Pengendapan } \\
(\text { jam })\end{array}$ & $\begin{array}{c}\text { Rendemen } \\
(\%)\end{array}$ & $\begin{array}{c}\text { Derajat } \\
\text { Esterifikasi } \\
(\%)\end{array}$ & $\begin{array}{c}\text { Viskositas } \\
(\mathrm{cP})\end{array}$ \\
\hline Prediksi & $1: 1.62$ & 1.70 & 4.45 & 71.14 & 39.99 \\
Hasil Penelitian & $1: 1.62$ & 1.70 & $4.43 \pm 0.25$ & $71.11 \pm 1.14$ & $40.5 \pm 1.73$ \\
Penyimpangan & & & 0.29 & 0.04 & 1.25 \\
\hline
\end{tabular}

Keterangan: rata-rata \pm standar deviasi dari tiga kali ulangan

Hasil prediksi ekstraksi pektin tepung kulit dan jerami nangka dengan perlakuan rasio bahan pengendap 1:1.62 dan lama waktu pengendapan 1.70 jam yaitu rendemen sebesar $4.45 \%$ sedangkan ekstraksi pektin hasil penelitian yang dilakukan didapatkan rendemen sebesar $4.43 \%$, pada respon derajat esterifikasi sebesar $71.14 \%$ sedangkan hasil penelitian yang dilakukan didapatkan derajat esterifikasi sebesar $71.11 \%$ dan pada respon viskositas oleh program sebesar $39.99 \mathrm{cP}$ sedangkan nilai viskositas pektin hasil penelitian sebesar 40.5 $\mathrm{cP}$. Nilai penyimpangan hasil verifikasi dari ketiga respon kurang dari $5 \%$ yang berarti hasil verifikasi sesuai dengan hasil prediksi program.

\section{Karakterisasi Pektin Hasil Optimasi}

Pektin hasil optimasi memiliki karakteristik seperti kadar metoksil $4.94 \%$, asam galakturonat $39.46 \%$, kadar abu $1.67 \%$, kadar air $10.35 \%$, kekuatan gel $9 \mathrm{~N}$, viskositas 40.5 $\mathrm{cP}$, sineresis $0.00167 \mathrm{~g}$.air/g sampel menit serta warna $L=59.9$., $a=11 ., b=17$. Pektin hasil optimasi kemudian dibandingkan dengan pektin komersial menggunakan uji t (t-test).

\section{SIMPULAN}

Optimasi proses ekstraksi pektin dari tepung kulit dan jerami nangka kajian rasio bahan pengendap dan lama waktu pengendapan menghasilkan titik optimal pada perlakuan rasio bahan pengendap sebesar 1:1,62 (v/v) dan pada perlakuan lama waktu pengendapan 1,70 jam. Hasil prediksi respon rendemen sebesar 4,45\%, respon derajat esterifikasi sebesar $71,14 \%$ dan respon viskositas sebesar $39,99 \mathrm{cP}$ sedangkan hasil verifikasi diperoleh nilai rendemen sebesar $4,43 \%$, nilai derajat esterifikasi $71,11 \%$ dan nilai viskositas sebesar 40,5 $\mathrm{cP}$. Selisih prediksi dan hasil verifikasi dari ketiga respon tersebut kurang dari $5 \%$ sehingga nilai hasil verifikasi titik optimum sesuai dengan hasil prediksi.

Hasil uji T ( $T$-test) menunjukkan bahwa nilai kadar metoksil, asam galakturonat, kadar air dan warna antara pektin hasil penelitian dan pektin komersial terdapat perbedaan yang nyata $(p<0,05)$ sedangkan terhadap nilai kadar abu, kekuatan gel, dan sineresis tidak memberikan perbedaan yang nyata $(p>0,05)$ terhadap pektin komersial.

\section{DAFTAR PUSTAKA}

Badan Pusat Statistik, 2016. Data Ekspor Impor Pektin. http://www.bps.go.id. Tanggal akses: 20/01/2017 
Bambang, B.S., Sumardi, J.A., Ismadi, P.H.B., dan Budiprayitmo. 1998. Pengaruh Konsentrasi $\mathrm{NaOH}$ dan Lama Perendaman yang Bervariasi terhadap Kualitas ATC. Jurnal Penelitian Perikanan 3: 33

Bath, S.V., Nagasampagi, B.A., and Sivakumar, M. 2005. Chemistry of Natural Products. Springer. New York.

Faravash, R.S., and Ashtiani, F.Z. 2007. The Effect of pH, Ethanol Volume and Acid Washing Time on The Yield of Pectin Extraction From Peach Pomace. International Journal of Food Science and Technology 42:10, 1177-1187.

Garna, H., Mabon, N., Robert C., Cornet, C., Nott, K., Legros, H., Wathelet, B., and Paquot, M. 2007. Effect of Extraction Conditions on The Yield and Purity of Apple Pomace Pectin Precipitated but Not Washed by Alcohol. Journal of Food Science. 72:1, C0019.

Kar, F., and Arslan, N. 1999. Effect of Temperature and Concentration on Viscosity of Orange Peel Pectin Solutions and Intrinsic Viscosity-Molecular Weight Relationship. Carbohydrat Polymers 40:4, 277-284.

Kementerian Pertanian. 2015. Statistik Produksi Hortikultura Tahun 2014. Direktorat Jenderal Holtikultura. Kementerian Pertanian.

Koh, P.C., Leong, C.M. and Noranizan, M.A. 2014. Microwave-Assisted Extraction of Pectin From Jackfruit Rinds Using Different Power Levels. International Food Research Journal 21:5, 2091-2097.

Manas, E., and Calixto, F.S. 1993. Ethanolic Precipitation: A Source of Error in Dietary Fibre Determination. Food Chemistry 47:4, 351-355.

Margani A.D. 2014. Pelarut dan Lama Ekstraksi Terbaik dalam Pembuatan Pektin dari Limbah Buah Nangka. Skripsi. Universitas Brawijaya. Malang.

McCready, R.M. 1970. Pectin: Methods in Food Analysis. $2^{\text {nd }}$ Edition. Academic Press. New York

Prabowo, I.D.P. 2017. Optimasi Esktraksi Pektin dari Air Rendaman dan Kulit Ari Kedelai Ditinjau dari Lama Waktu Perendaman Kedelai dan Lama Waktu Koagulasi Pektin. Skripsi. Universitas Brawijaya. Malang

Pudjaatmaka, A.H. 1994. Buku Ajar Vogel: Kimia Analisis Kuantitatif Anorganik. Buku Kedokteran EGC. Jakarta

Raissi, S., and Farzani, R.E. 2009. Statistical Process Optimization Through Multi-Response Surface Methodology. World Academy of Science, Engineering and Technology 3:3, 267-271

Ranganna. 1977. Manual of Analysis for Fruit and Vegetable Products. Mc Graw Hill. New Delhi

Sharma, B.R., Naresh, L., Dhuldhoya, N.C., Merchant, S.U., and Merchant, U.C. 2006. An Overview on Pectin. Times Food Processing Journal. 23:2, 44-51.

Schultz, T.H. 1965. Determination of the Degree of Esterification of Pectin. In Methods Carbohydrate Chemistry. Vol. 5 (R.L. Whistler, ed.) pp. 189-194. Academic Press. New York.

Sudarmadji, S., Haryono, B. dan Suhardi. 1997. Prosedur Analisis untuk Bahan Makanan dan Pertanian. Liberty. Yogyakarta.

Willat, W.G.T., Paul, K. and Jorn, D.M. 2006. Pectin: New Insights Into An Old Polymer Are Starting To Gel. Trends In Food Science and Technology 17:3, 97-104.

Yapo, B.M., Wathelet, B., and Paquot, M. 2007. Comparison of Alcohol Precipitation and Membrane Filtration Effects Sugar Beet Pulp Pectin Chemical Features and Surface Properties. Food Hydrocolloids 21:2, 245-255.

Yuwono, S.S., dan Susanto, T. 1998. Pengujian Fisik Pangan. Universitas Brawijaya. Malang. 